\title{
A farda "siri cozido" e a "branquinha": narrativas de vida de um paciente militar alcoolista
}

\author{
Elizabeth Espindola Halpern ${ }^{1}$ e Ligia Maria Costa Leite ${ }^{2}$ \\ Instituto de Psiquiatria da \\ Universidade Federal do Rio de Janeiro (Rio de Janeiro, RJ)
}

\begin{abstract}
As narrativas de vida de um militar alcoolista, paciente de um ambulatório especializado em dependência química da Marinha do Brasil, possibilitaram a compreensão de aspectos que contribuíram para a construção de sua adição. As entrevistas revelaram a participação de processos socioculturais que influenciaram sua forma de beber, sobretudo no ambiente laboral, representados por duas categorias centrais: a farda "siri cozido" (cor alaranjada) e a "branquinha" (cachaça), relacionadas à profissão militar naval e ao consumo de etílicos. A análise dos dados revelou como ele significou seu processo de adoecimento e cura, assim como as representações sobre si, em torno da trajetória de envolvimento com o álcool e com o trabalho. Produziram-se generalizações analíticas significativas, sugerindo que as experiências de um único militar podem ajudar a entender a situação de outros militares, questionando-se o papel dessa instituição na construção do alcoolismo.
\end{abstract}

Palavras-chave: Condições de trabalho, Alcoolismo, Militares, Cultura.

The "cooked crab" uniform and the "branquinha": life narratives of a military alcoholic patient

Life narratives of an alcoholic military man, patient of an outpatient unit specialized in chemical dependency from the Brazilian Navy, provided an understanding on aspects which contributed to the construction of his addiction. The interviews revealed the participation of sociocultural processes that influenced his way of drinking, above all in the work environment, represented by two central categories: the "cooked crab" uniform (orange colored) and the "branquinha" (sugar cane brandy), related to the military naval professional and to alcohol consumption. Data analysis revealed how he attributed a meaning to his illness and healing process, as well as his representations of himself, with regard to the path of his involvement with alcohol and labor. Significant analytical generalizations were produced, suggesting that the experiences of a single military man can help understanding the situation of other military men, questioning the role of this institution in the construction of alcoholism.

Keywords: Work conditions, Alcoholism, Military men, Culture.

\section{Introdução}

A s narrativas de vida de um Fuzileiro Naval, paciente do Centro de Dependência Química (CEDEQ) do Hospital Central da Marinha (HCM), com o diagnóstico de transtorno mental e comportamental devido ao uso de álcool, permitem o exame de aspectos socioculturais envolvidos na construção desse distúrbio. Por meio de sua experiência singular, objetiva-se conhecer mais sobre o ethos e a visão de mundo de um universo mais extenso, a saber, o de outros pacientes usuários de álcool do CEDEQ que pertencem, predominantemente, à classe ${ }^{3}$ das $\operatorname{Praças}^{4}$ da Marinha do Brasil (MB). Espera-se que as

\footnotetext{
1 Psicóloga. Doutoranda do Programa de Pós-Graduação em Psiquiatria e Saúde Mental do Instituto de Psiquiatria da Universidade Federal do Rio de Janeiro (IPUB/UFRJ). Mestre em Saúde Coletiva pelo Instituto de Medicina Social da UERJ.

2 Doutora em Comunicação pela Universidade Federal do Rio de Janeiro (UFRJ). Professora do IPUB/UFRJ.

3 A noção de classe será aplicada segundo a concepção de Bourdieu (2002) quando se refere aos conjuntos de agentes que ocupam posições semelhantes e que, ao ser colocados em condições e submetidos a condicionamentos semelhantes, terão grandes chances de apresentar atitudes, interesses, práticas e tomadas de posição semelhantes.

4 Soldados, Marinheiros, Cabos, Sargentos e Suboficiais.
} 
vivências desse militar possam iluminar questões mais amplas relativas à vida militar que envolvem o consumo de etílicos no ambiente laboral ${ }^{5}$.

\section{Contexto}

A criação do CEDEQ, em 1997, um ambulatório encarregado do atendimento aos usuários de drogas, representa uma iniciativa pioneira da MB no âmbito das Forças Armadas brasileiras, um marco que refletiu o início oficial das ações voltadas à dependência química ao contingente naval. Localizado no HCM, conduzido por equipe multiprofissional com formação em Psicologia, Psiquiatria e Serviço Social, no CEDEQ são realizadas terapias em grupo, individual e tratamento medicamentoso.

Apesar de o CEDEQ estar aberto a todo o pessoal da MB, a partir de 18 anos, a totalidade $(100 \%)$ dos pacientes é composta por Praças, uma maioria numérica da organização naval que se encontra na base da pirâmide da cadeia de Comando. Em geral, suas atribuições relacionam-se à execução das tarefas de manutenção e operação dos equipamentos e à conservação de compartimentos de suas unidades militares, distribuídas de acordo com suas habilitações, conforme dispõe o Estatuto dos Militares (Brasil, 1980). Os Oficiais, por sua vez, raramente vão ao CEDEQ, optando por consultas particulares e medicamentosas. Fronteiras simbólicas parecem servir de linha divisória entre Praças e Oficiais, além de haver uma demarcação baseada na ocupação e no grau hierárquico.

O tratamento em grupo progride ao longo de cinco etapas: Grupo Motivacional, Fases I, II e III e Grupo de Consolidação, cada qual com um número mínimo de sessões e atividades a serem cumpridas, bem como metas a serem atingidas. Em média, a duração do tratamento é de um ano e meio, dependendo da evolução individual, em função do alcance da abstinência e de reformulações na forma de agir e pensar.

\section{Método e processo de coleta e interpretação de dados}

Trata-se de uma pesquisa qualitativa realizada por meio de um estudo de caso único, típico ou representativo e explanatório (Yin, 2005), de modo a: compreender a complexidade da construção do fenômeno do alcoolismo no contexto do tratamento ambulatorial em uma unidade militar naval; e estabelecer correlações com as vivências dos demais pacientes inseridos no mesmo cenário. Para tal, determinou-se um foco analítico e comparativo do ethos e da práxis a partir de dois eixos: a trajetória de envolvimento com a substância etílica e com o labor, imersos no estilo de vida urbano (O'Donnell, 2008). Desse modo, buscou-se analisar como se estabelecem as redes sociais (networks) baseadas nos critérios de "escolha" de "campanhas" (colegas) com os quais desenvolvem afinidades e produzem interações no campo da sociabilidade, também associadas ao uso do álcool.

As entrevistas foram conduzidas com a ferramenta da narrativa de vida, a partir da construção de um modelo semiestruturado (open-ended), para que um fuzileiro naval (FN), paciente alcoolista do CEDEQ, contasse sua história de sua própria maneira (Groleau, Young \& Kirmayer, 2006). Assim, o número de entrevistas e sua duração não foram pré-determinados, possibilitando que o próprio processo de interação ditasse a profundidade, duração, rumo e

5 Esta pesquisa foi deferida pelo Comitê de Ética em Pesquisa do Hospital Naval Marcílio Dias, cadastro FR no 306557 e CAAE nº 0021.0.221.000.09, em 14 de dezembro de 2009. 
intensidade. Isso permitiu que o militar abordasse livremente sua história de vida, incluindo outras questões que julgou importantes, sem o compromisso de acompanhar a cronologia dos fatos, mas sua relevância, em conformidade com a perspectiva construtivista, de modo que entrevistador e entrevistados tornam-se ativamente envolvidos na construção de significados de suas vivências (Holstein \& Gubrium, 1995). Adicionalmente, as entrevistas foram precedidas por uma negociação ou explicitação quanto aos objetivos da pesquisa, deixando claro quais eram os papéis das duas partes (pesquisador-paciente).

A construção de questões não estruturadas permitiu o surgimento de processos socioculturais que indicaram quais foram os elementos mais marcantes na experiência do entrevistado. Com efeito, ao longo de suas narrativas, foram progressivamente identificados dois eixos principais a partir dos quais suas experiências foram construídas: a farda "siri cozido" (cor alaranjada) e a "branquinha" (cachaça). A "farda siri cozido": alaranjada, cor chamativa e bonita, que enchia os olhos do jovem que sonhava cantar e encantar garotas, tal qual um herói dos filmes românticos de guerra. Sonho de menino de trajar o uniforme diariamente exibido pelos militares que circulavam perto de sua residência, entrando e saindo dos Batalhões em carros de combate. A "branquinha" (cachaça): bebida quente, "energizante", condição de descontração e de alegria entre colegas de farda, que tanto o ajudou a seduzir garotas nos bailes como a cair em desgraça nos becos.

Com o estudo de caso único se espera produzir generalizações significativas, ou seja, generalizar um conjunto particular de resultados em relação a uma concepção mais abrangente, que seja capaz de identificar o que pertence à ordem do coletivo, ainda que não se pretenda esgotar todas as possibilidades sociais nesta oportunidade. Com efeito, espera-se ajudar a compreender outros pacientes do CEDEQ e a sondar sobre a situação de outros militares que não são pacientes do CEDEQ, inacessíveis à pesquisa.

Alguns estudiosos já reconheceram a existência de resistências ao estudo das instituições militares brasileiras (Coelho, 1976; Castro, 2004). A dificuldade de acesso parece se acentuar pelo fato de esta pesquisa abordar um assunto delicado: o consumo de bebidas na MB. Assim, este estudo procurou fixar-se em um campo acessível por conta da posição social de uma das pesquisadoras, que é chefe do CEDEQ, oficial da MB e psicóloga. Na verdade, a questão da posição da pesquisadora tornou-se outro aspecto metodológico a ser explicitado: a transparência da descrição do processo de pesquisa e a análise de seus efeitos exigem o esclarecimento da sua posição, tendo em vista que afetam os próprios resultados. De fato, seu posicionamento facilitou a própria autorização para a condução da pesquisa, por desfrutar uma oportunidade singular de coleta dos dados. Yin (2005) considera que o ponto de vista de alguém de "dentro" revela o que é potencialmente possível em determinada sociedade ou grupo; permite capturar as circunstâncias e as condições no cotidiano da vida do sujeito em questão. Portanto, acredita-se que elas possam ilustrar uma dinâmica presente na vida de outros militares, também.

A coleta de dados foi realizada por meio de entrevistas individuais no próprio CEDEQ, local onde o militar em questão faz tratamento há alguns anos. Atualmente, de forma voluntária, ele permanece em acompanhamento ambulatorial, no Grupo de Consolidação (póstratamento), em abstinência há mais de sete anos.

A interpretação dos dados foi feita por meio da análise de categorias, daquelas que emergiram de forma singular no seu discurso, permitindo entender como se deu a construção de significados em compasso com a análise da trajetória. Isso possibilitou investigar os significados que ele atribuiu ao seu processo de adoecimento, as representações sobre si em torno dos dois eixos já explicitados: trajetórias de envolvimento com a substância etílica e com o labor. 


\section{Adsumus: marca identificatória}

O lema em latim dos FNs, adsumus ("aqui estamos!"), tornou-se uma ideia construtora da identidade grupal que os diferencia de outros militares da $\mathrm{MB}$, cooptando para o delineamento da autoimagem individual, servindo de marca identificatória, legitimada socialmente e modelando comportamentos a serem seguidos. Segundo Silva (1961), o lema vivo adsumus é assimilado no cotidiano através de proclamações tais como ser: "pau pra toda obra", "máquina que cose de todos os lados" e "soldado superior ao tempo". Famosos pela bravura, podendo agir em terra e no mar, sentem-se vaidosos com a crença de que são soldados excepcionais, mais valentes e adestrados do que os outros. Movidos pelo lema, alardeiam sua fama, ostentam sua bravura, sentem-se respeitados e temidos. "Fuzileiro naval: homem que vive na pele de leão, mas que gostaria de ser simples cordeirinho".

Esse sentimento foi desenvolvendo-se ao longo de um percurso, desde quando os FNs foram responsáveis pela salvaguarda da Família Real no Brasil até a atualidade, com a denominação recebida, em 1932, de Corpo de Fuzileiros Navais da MB. A fama favorável, que já atraiu jovens aventureiros em direção à farda, foi sedimentada em um período mais recente, após uma série de mudanças nessa corporação que se operaram no tempo, destacando-se as exigências quanto à saúde, procedência e qualidade dos candidatos que passaram a ser feitas no início do século XX. Desde então, a vida do FN passou a ser "dar serviço", fazer exercícios e seguir a disciplina, em constante prontidão. "Quem não prestava, quem era fraco, quem não aguentava o rojão, caía fora, só os 'espartanos' continuavam” (Silva, 1961, p. 41).

\section{Prestes: o caso de um fuzileiro naval alcoólico}

O lema adsumus, materializado no "uniforme", e o hábito progressivo de consumir etílicos, representado pelo "copo", parecem ter contribuído para formar a identidade do Cabo Fuzileiro Naval (CB-FN) Prestes (nome fictício). Com suas narrativas, almeja-se compreender como suas condutas foram sendo arquitetadas, algumas obedecendo os padrões esperados, ao passo que outras são consideradas desviantes. Para tal, três etapas de sua vida serão examinadas: apogeu, declínio e assimilação.

\section{Apogeu}

$\mathrm{Na}$ fase de apogeu, seus relatos evidenciam uma época permeada por fantasias que supervalorizavam a vida militar, na qual o consumo de álcool participou como elemento coadjuvante, associado à alegria e farra entre companheiros.

Menino que virou homem, quase gigante, de cor negra, bem negra, com olhos luzentes de jeito infantil. Quando moço, corrente e cadeado vermelhos prendiam seus pés para não fugir para os bailes, uma humilhação imposta por um pai distante. Essa é a história de vida de um homem que rompeu amarras para ser Fuzileiro: marchar, participar de manobras, viver aventuras, ter um ideal: de lutar e proteger a pátria. Suas vivências apontam para a existência de um processo de marginalização que acompanhou o desenvolvimento do seu alcoolismo. Vício que se instalou de forma insidiosa, porém, previsível, em razão dos vieses que atravessaram suas experiências, formando-o e conformando-o, moldando sua natureza por mãos coletivas: grupos, camaradas, superiores hierárquicos, tradições navais e normas ambivalentes: 
Eu era garoto, morava na Ilha do Governador, onde se concentra a maioria das OM de Fuzileiros Navais. Escutava o barulho de sirenes. Depois descobri que eram batedores, iam pras manobras. Via pessoas fardadas. Ficava curioso! Queria fazer parte da "turma de fardas". Queria vestir o camuflado [uniforme]! Gostava do uniforme "siri cozido", meio alaranjado, achava deslumbrante! [em tom de encantamento] Chamava mais atenção do que o branco, o "da gola" [referindo-se ao uniforme usado na Armada].

Deslumbrado com a aparência do uniforme, ele o considerava uma isca capaz de fisgar os jovens sonhadores de um modesto bairro carioca. Prestes foi um dos muitos jovens atraídos pelas cenas de cinema para ingressar na vida militar. A imagem de Elvis Presley uniformizado, ao som de sua guitarra, embalava seus sonhos fuzileiros. Eram filmes românticos de guerra, nos quais o ator estava sempre rodeado de garotas, música e tumultos. Eram imagens de heroísmo, associadas a virilidade, valentia e destemor, sedutores aos seus olhos sonhadores: "Quando entrei, ainda não tinha filme de Rambo [personagem de cinema protagonizado por Sylvester Stallone], Schwarzenegger [protagonista de filmes de ação]. Só depois é que eles apareceram. Aí, eu ia empolgadíssimo pras manobras!". Garotas, conquistas e brigas faziam parte do enredo de um FN, nem sempre bem afamado:

Na Ilha [do Governador], tinha o mito de que Naval não prestava. Pai nenhum queria que suas filhas namorassem Naval; ou eram odiados pelos pais, irmãos, rivais, ou eram amados por muitas mulheres! Onde tem Naval, tem briga, tem confusão.

O "mito" relacionado à sua má fama, no meio social, forçava as moças a se manter afastadas deles, obrigadas a mudar de lugar nos ônibus para "não ser confundidas" (Rodrigues, 2004, p. 60). "O uniforme garance [uniforme de gala com o dolman vermelho], que tanto entusiasmo causava ao povo nos dias de parada, era motivo de temor quando os fuzileiros se apresentavam de licença, isoladamente, em certos cantos da cidade" (Silva, 1961, p. 93). Contudo, Prestes entrou na MB em uma época em que ser FN produzia um status valorizado perante seu grupo sociofamiliar. Com 19 anos, ao ingressar no Centro de Recrutas, orgulhou-se por ter recebido mais de 20 cartas de congratulações: "Teve gente oferecendo até talão de cheque, cartão de banco! Senti um poder, crédito, todos me convidando pra comprar nas lojas. A Marinha me deu liberdade: conquistei essa liberdade! Meu pai não podia mais me travar". De acordo com sua percepção, a Marinha o libertava da corrente e cadeado vermelhos.

Nos primeiros tempos da carreira, Prestes bebia a bordo com certa timidez, pois era um soldado muito moderno (com pouco tempo de Marinha e baixa graduação) e não se sentia seguro para beber em demasia no trabalho. Depois, passou a fazer parte dos "clubinhos", cujos integrantes eram selecionados dentre aqueles que iam para as manobras e que estavam interessados em beber juntos durante as operações militares:

Eu conheço fulano, que conhece beltrano, e assim por diante. Não era escancarado. A gente descansava no estacionamento e ia procurar algum conhecido pra arrumar bebida, alguém com livre acesso pra poder buscar. Se a patrulha saísse mais tarde, tomava um golinho antes da manobra. Só bebia quem tava no "clubinho". Era manobra de mais de 800 homens. Só dá pra se aproximar se o sujeito já conhece, se já tem intimidade. No "clubinho" tinha muita gente, uns 50 ou mais.

Depois que entrou na $\mathrm{MB}$, conta que passou a fazer parte do "time que não presta" do bairro em que morava: "Tinha aquelas festas, gandaias, Virgem Santa!". O álcool já era importante, bebia bastante, mas não de forma explícita. Às vezes se embriagava, mas tinha o cuidado de estar cedo no trabalho. Seu envolvimento com etílicos se intensificou quando foi servir no Batalhão Naval e ao fazer parte do "sindicato" [grupo de bebida]: 
Grupo coeso! Rezávamos pra chover de segunda a quinta. "Bem que podia ter uma chuvinha hoje! Bem que podia ter uma chuvinha hoje!" [reproduzindo a fala entre eles]. Se chovia, era certo: botava a capa de chuva e ia pro pátio, cada um com uma garrafa.

"Quantos eram nesse grupo?" [entrevistadora].

Era um pelotão, uns 50 !

"Todos nessa voga?" [entrevistadora].

Não, aí tinha uns que não bebiam, os evangélicos; mas o grupo fechado, era de uns 30 !

As experiências relatadas ilustram como, no seio de um grupo, um sistema compartilhado de crenças e valores se desenvolve, assim como uma identidade comum e solidariedade. Esse é um aspecto que já foi identificado por Velho (1981), particularmente ao se referir aos membros de grupos que se organizam em torno de práticas e comportamentos tidos como condenáveis. Para Goffman (1963/2008), esse compartilhamento possibilita a constituição de uma identidade social, impregnada de estigmas negativos, em resposta à manipulação da própria sociedade. Segundo ele, mais do que se referir a um atributo profundamente depreciativo, o estigma se relaciona a uma linguagem de relações, e não de atributos; refere-se a uma forma particular de relação entre atributo e estereótipo. Em decorrência, segundo Becker (1977, p. 84), uma subcultura desviante é constituída: "[...] um conjunto de perspectivas e compreensões sobre como é o mundo e como lidar com ele, e um conjunto de atividades regulares baseadas nessas perspectivas".

Paulatinamente, o beber de Prestes foi se amalgamando ao prazer, imiscuído nas tarefas marinheiras, com o aval de superiores hierárquicos, e inserido na rotina. Apesar do trabalho árduo e até braçal, o sentimento predominante era de alegria: "Trabalhava num sol quente do caramba, a gente trabalhando, quebrando aqueles concretos de 1908, dessa grossura! Nada nos abalava, a gente tava sempre rindo, brincando".

Aconteciam as famosas empreitadas! O Comandante falava assim: "Ó, vocês têm 15 dias pra terminar esse serviço. Se vocês terminarem em 14, vocês ficam um em casa; se vocês terminarem em um, vocês ficam 14 em casa". Aí, a gente pegava equipe de cinco e seis...

"Esses prazos que ele dava, eram adequados?" [entrevistadora].

Adequados! [com segurança].

"E onde é que o álcool entrava nisso?" [entrevistadora].

Ah, pra acelerar o trabalho! Dava mais disposição, força; fazia com que a gente fizesse as coisas mais rápido.

Observa-se que o alcoolismo, enquanto "desvio", é fruto de uma mudança nos padrões de comportamento e nas perspectivas do indivíduo, obedecendo a uma sequência de passos: para que o sujeito se transforme em um consumidor crônico de etílicos, é preciso que a droga esteja disponível, bem como experimentá-la e continuar a utilizá-la (Becker, 1977). Caso a instituição venha a facilitar esse consumo, incentivando-o e imprimindo uma valoração positiva a ele, as chances de o militar tornar-se um dependente do álcool serão potencializadas. O álcool tornou-se figura central na vida de Prestes, com sol, com chuva, com autorização explícita ou às escondidas:

Em dia de chuva, ninguém ficava supervisionando. Botavam a gente pra tirar erva daninha do campo. A gente botava o banquinho, sentava, pegava os ferrinhos, ficava ali, catando. Aquela capa cobre tudo e a garrafa ficava ali embaixo. Doutora, faltava tudo no meu armário, menos uma capa de chuva! Se não tivesse uma capa de chuva, como é que vai fazer? Não tinha como! [rindo]. Ameaçou chover: capa de chuva! 
Essa experiência ilustra como as narrativas de vida de um indivíduo podem captar certas características do grupo, evidenciando formas típicas de comportamento, inclusive os proscritos. "Mesmo uma biografia excepcional é capaz de lançar luz sobre contextos e possibilidades latentes da cultura" (Alberti, 2004, p. 23). A constatação do uso do álcool em âmbito laboral, frequente e disseminado, coloca em questão seu caráter de desvio ou de excepcionalidade. A postura institucional ambivalente, de rechaço e de apoio ao consumo de álcool, deixa os militares confusos, sobretudo ao se constatar que a MB atua como facilitadora. Se, por um lado, o sujeito vai aprendendo a ser militar, a trajar o uniforme, enfim, a "vestir a camisa", por outro lado, ele aprende a beber. Ainda que Prestes ingerisse álcool desde a sua vida civil pregressa, na Marinha esse consumo se tornou uma experiência comunitária, alicerçando relacionamentos, conferindo um espírito de corpo, um tipo de cumplicidade e um modo de sociabilidade. Cabe ressaltar que as redes de sociabilidade são reguladas por uma etiqueta modeladora de gestos e emoções e formas de interação. Afetados por um conjunto sutil de coerções, os indivíduos vão sendo moldados na esfera profissional, submetidos a um controle social direto sobre seus comportamentos, conformando-os, de modo global, às regras impostas (Elias, 1987).

A formação de um grupo de pagode foi o resultado da combinação de sua trajetória de militar e do envolvimento com etílicos, com música, noitadas e mulheres. A "branquinha" (cachaça), a "lourinha" (cerveja) e a "bebida quente" (bebida destilada) tornaram-se membros de sua "família", íntimos, presentes nas faxinas (trabalho), nos socos (passeios à procura de mulher), nas licenças (autorização temporária para o afastamento do serviço) e no rancho (refeitório). Nos primeiros anos da vida militar, a bebida era associada a alegria, festas, farras, "mulheril" (modo marinheiro de se referir às mulheres), manobras e aventuras. Contudo, até então, ele ainda não percebia que o álcool estava assumindo, insidiosamente, a gerência de sua vida, até que um evento funcionou como divisor de águas, ceifando sua carreira, arremessandoo em direção à cachaça, ao comportamento de risco e às contravenções disciplinares.

\section{Declínio}

A "carona da morte", conforme denominou o acidente de carro que sofreu a caminho do Batalhão, que resultou na perda da visão esquerda, foi o começo do declínio, de um período de "sucessos". Por estar a caminho do trabalho, a MB considerou que essa perda tinha relação de causa e efeito com o serviço.

Após mais de dois meses de internação hospitalar, descobriu-se cego do olho esquerdo, sofrendo, segundo o resultado do Inquérito Sanitário de Origem (ISO), de amaurose por sequela de trauma ocular, com ruptura de coroide, adquirida em ato de serviço, passando a ter visão monocular. Cabisbaixo, relatou: " $E$, consequentemente, minha visão se foi, consequentemente, minha visão se foi. Foram 68 dias de internação. Eu sei que eu já saí muito triste de lá [hospital], comecei a ficar triste. [pausa] Comecei a beber, chorar, chorar". Adicionalmente, seu estado geral se agravou porque, segundo explicou, sua ausência no trabalho, durante a internação hospitalar, teria sido inicialmente considerada deserção.

Estranhamente, apesar de ter ficado cego de uma vista, foi considerado apto para o Serviço Ativo da Marinha (SAM), com recomendações: não poderia participar das manobras operativas, marchas, formaturas, serviços que exigissem visão em profundidade e binocular, nem dar o serviço noturno, realizar serviços pesados ou participar do treinamento físico militar. Relembrou a fala de um médico:

O Doutor me disse: "Se você fosse 'boy de Marinha' [novato], eu mandava você lá pra cima [Junta de Saúde], e você ia ser reformado [definitivamente incapaz por motivo de saúde]. Como você é antigo, eu vou deixando você em qualquer buraco aí até cumprir seu tempo". 
Prestes exclamava aos superiores hierárquicos e médicos: "Mas eu não tô enxergando!". Inconformado, explicou que a perda de visão nunca constou no Atestado de Origem ${ }^{6}$. Ao ouvir sua explicação, o juiz militar, diante da acusação de deserção, resolveu:

Você não é caso de cadeia! Vou mandar você pro tratamento lá no hospital que vocês têm. O senhor está sendo julgado por um ato criminal, aconselho o senhor a buscar seus direitos administrativos [reproduz o pronunciamento do magistral militar].

A partir de então, a associação do álcool como vivência de prazer foi substituída pela necessidade de extravasar a raiva e impotência. $O$ álcool tornou-se central em sua vida: companheiro, mulher, amigo e confidente:

Aí, eu comecei a ver que o sistema não era verdadeiro, comecei a "jogar tudo pro alto"! Ia quando queria; quando num tava a fim de ir, não ia. Dormia e ficava na porta do quartel. Ou ia, bebia, saía, ia embora. Comecei, com o perdão da palavra, comecei a bagunçar, comecei a tomar cadeias, a faltar ao quartel, faltar ao quartel, faltar ao quartel. Faltei, faltei!

"O que você fazia quando faltava?" [entrevistadora].

Bebia, ficava na rua, na noite. Hoje, evito passar por ali na beira da praia. Nem amarrado de cobre! Não quero saber daquele pedaço, toda aquela orla marítima. Acontecia briga, traições. Ali, tem um hotel de frente pro quartel de GLS, Clube de Mulheres, prostíbulo. Eu ficava ali: bebendo, frequentando. Nesse momento, eu estava completamente desnorteado. Eu já "tava ali no automático". Cheguei num estágio que não era mais raiva, não era mais vista, não era mais sofrimento, não era mais alegria! Nada! Era só a vontade de beber!

Meio lá, meio cá, apto para a carreira, mas com restrições laborativas, seus dias de glória pareciam ter chegado ao fim: manobras na selva, incursões nos morros, fuzil em punho, tornaram-se histórias do passado. Fuzileiro pela metade, carreira fraturada, estagnado como Cabo, ansiava por uma chance remota de promoção a Sargento. O álcool apoderou-se de seu cotidiano, sedando sua raiva e prometendo transmutá-la em gargalhadas gostosas, com a cumplicidade dos campanhas (colegas), compartilhando o churrasquinho e a cerveja, ali mesmo no quartel, ou nos arredores, nos trailers. "Foi aí que minha vida embolou todinha!", concluiu, deixando o silêncio dominar o ambiente da entrevista. Thompson (1992) esclarece que, na história de vida, deve ser levada em conta a eloquência dos silêncios e evasões, enfim, seu significado, ainda que haja uma tendência a crer que os depoimentos orais sejam imprecisos e fantasiosos.

Naquela época, morava com pessoas sem teto, virando noites e mais noites, dormindo em mesa de bar, em praça, puxando briga. Uma confusão do caramba! Ficava ali no meio deles, depois dormia por lá mesmo. Fiquei meio psicótico com negócio de doença. Passei a fazer uma sequência de HIV, HIV, HIV, de três em três meses. Fiz direto! Eu não acredito que, com a vida que eu levei, que eu não tenha contraído uma doença.

"Com que tipo de pessoas você se relacionava?" [entrevistadora].

Com as piores possíveis: prostitutas, com as pessoas que conhecia. Eu tenho vergonha de falar. Só com os dos grupos de risco. E eu não adquiri nada! [fala com ar de espanto].

Uma avalanche de lembranças eclodiu: confusas, delicadas, traumáticas, sofridas, muitas delas vívidas, outras difusas, pela dor ou vergonha. A entrevistadora pôde notar seu constrangimento ao detalhar o que se passou naqueles tempos, talvez pela sua posição social e

6 Documento que é confeccionado quando o militar se envolve em acidente em razão de "ato de serviço" que desencadeie incapacidade física temporária ou definitiva. Ele deverá ser redigido pelo mais antigo que testemunhou o acidente ou pelo próprio militar se estiver sozinho na ocasião. 
hierárquica, quem sabe pelo conteúdo em si, trazendo-lhe embaraço ao recapitular. As narrativas acionam uma memória que é compreendida como cultural e socialmente mediada. Portanto, ela não é uma representação neutra, ela é responsável tanto pela recordação como pelo esquecimento de certos atos - possui dimensões semânticas e pragmáticas. Lambek (1996) entende que as narrativas são veículos da memória: recordar é uma prática simbólica.

\section{Assimilação}

A fase de assimilação refere-se a uma negociação da realidade. As experiências adquiridas na vida social produziram choques, abalando suas fantasias, obrigando-o a rever seus projetos de vida. Como Velho (1981) esclarece, nas sociedades complexas, os indivíduos são levados a negociar com o mundo circundante, que é demarcado, histórica e culturalmente, por um campo de possibilidades, para que possam colocar em marcha seu processo de individuação. Este, por sua vez, somente se faz a partir da referência ao outro, ou seja, das experiências socioculturais, que oferecem um rol de códigos e símbolos passíveis de manejo, porém, circunscritos pelas balizas normativas hegemônicas. Esse tipo de negociação conduziu Prestes a um tipo de conversão, onde foram negociados significados e situações, passados e presentes, fazendo-o deslocar-se de uma posição social a outra. Essa conversão requereu a passagem entre sistemas simbólicos, onde é capital a mudança de comportamento para transformar-se em alcoólico passivo (alcoólico que não bebe). De fato, nessa jornada, operaram-se mudanças na sua forma de consumir bebidas e nas suas relações de sociabilidade. Outro sistema de crenças foi sendo alicerçado, viabilizado pelo exercício constante de uma negociação perante as crenças e valores morais hegemônicos que imperam na sociedade (Garcia, 2004).

Içado do "fundo do poço" pela imperativa sentença judicial, a voz do magistrado ainda ressoa nas lembranças de Prestes. Voz redentora que determinou o tratamento ambulatorial compulsório, enunciando um: "Basta!". E, assim, segundo Velho (1981; 1994), estabeleceu-se um acordo sobre o embate entre a fragmentação e a totalização. Prestes foi "salvo pelo gongo", "salvo pela palavra". Vocábulo que lhe deu o "passaporte" para ingressar em uma nova rede de significados (web of meanings), conforme propõe Geertz (1973), em um fluxo contínuo onde encontrou outro sentido para sua vida - uma linguagem. Semântica redatora do seu projeto pessoal, conciliando caos e ordem, "farda" e "farra", tal qual fênix rediviva. Todavia, durante muito tempo, as perdas representadas pela ausência da visão esquerda e pela "amputação" de sua carreira, prevaleciam em sua experiência emocional:

Eu não conseguia pensar em outra coisa que não fosse Marinha. Eu gosto da coisa, eu gosto! Eu posso, durante um período, ter-me desviado por completo. Mas eu gosto da coisa!

"De que coisa?" [entrevistadora].

De estar aqui, do militarismo, por mais difícil que ele seja, eu gosto! Mas eu tenho que me desvincular. Eu cheguei à conclusão de que está sendo difícil me desvincular. Ao mesmo tempo que eu falo que eu quero ir embora, eu também quero ficar! Porque, no fundo, eu ainda tenho alguma esperança de, num "abracadabra", eu voltar a ser como eu era, pra fazer tudo: manobra, correr, saltar! [fala com empolgação].

Gradualmente, ele começou a enxergar a MB para além da visão romântica e heroica inicial que o atraiu quando jovem, constatando que ela o "encostou". A administração naval nem autorizava seu prosseguimento na carreira nem sua reforma.

O que você quer? [entrevistadora].

Voltar para ativa, Doutora! [exasperado].

Voltar, voltar! E, voltando, ter todos os privilégios de quem está. 
Contudo, concorda que, se não tivesse se tratado no CEDEQ, por ordem judicial, não teria se "curado": "Ir pro fundo do poço foi a única forma de eu me curar".

Apesar das evidentes perdas, de saúde, prestígio e na carreira militar, ele percebeu o ganho conquistado: a sobriedade. Embora tenha sido afastado do epicentro da vida operativa, houve um proveito paralelo.

"Perder a visão pode ter te ajudado a ganhar sua vida?" [entrevistadora].

Tenho que parar pra analisar esse tipo de coisa... [fica pensativo e conclui]. Se for olhar por esse lado, eu creio que sim! Se uma coisa puxa a outra... Senão seria: "Aqui jaz um Sargento! Morreu atropelado, caiu, sei lá!".

Essa reflexão sugere que houve uma função terapêutica no próprio processo das entrevistas, o "milagre da palavra", segundo Dejours (1999). Prestes se deu conta de fatos ou raciocínios que ele "sabia sem saber", ou seja, antes de suas palavras serem emitidas, elas não existiam para ele mesmo, ganhando existência mediante a construção desse espaço de fala e escuta.

\section{Resultados: aprendendo a ser um outsider}

A farda de cor "siri cozido" e a "branquinha" emergiram como duas vertentes importantes que afetaram o Fuzileiro em estudo. Seu relato revela que as circunstâncias que envolveram o exercício da profissão e as práticas de ingerir álcool a bordo foram aprendidas, ou melhor, apreendidas, fundamentais para que ele viesse a se tornar um outsider (Elias \& Scotson, 2000). Aprender a ser militar, a assumir os predicados de FN, ocorre no quartel, em grupo, constituindo uma mentalidade e um agir. Mais do que existir uma aprendizagem formal, ocorre uma assimilação silenciosa, insidiosa e progressiva. De fato, cada grupo e sociedade têm hábitos que lhes são próprios; na $\mathrm{MB}$ ocorre um treinamento que modela uma atitude corporal. "Não há técnica e tampouco transmissão se não há tradição" (Mauss, 1974, p. 217). Mauss esclarece que a técnica é um ato tradicional eficaz, incluindo-se as técnicas corporais e as de consumo. Com efeito, Prestes descreveu como foi aprendendo a beber no contexto militar:

\footnotetext{
Eu tava numa manobra. Chovia, chovia. O Sargento mandou eu ir pro vilarejo pra arrumar coisa pra gente comer, não aguentava mais abacaxi e enlatado. Foi quando notei que ele tava diferente. Olhou pra mim, disfarçou, olhou de novo. Aí, falou: "Boy, chega aqui, bebe aqui!", botando cachaça na caneca do cantil. "Agora você já bebeu, não vai poder mais me entregar. Nem eu entrego você, nem você me entrega". Foi a primeira vez que bebi cachaça na vida e na Marinha. Foi estranho, com medo, esquisito, por causa das ameaças.
}

Acredita-se que essa forma de aprendizagem, tal como é identificada por Mauss, também se faça em relação ao álcool, evidenciando a formação de um habitus alcoólico (Halpern, Ferreira \& Silva Filho, 2008). Em outras palavras, trata-se de padrões de comportamento relacionados ao ato do beber que vão sendo incorporados, passando a fazer parte do ser do indivíduo, relacionados ao universo da organização naval e amparados na cultura marinheira que, em certas ocasiões, incentiva seu uso. $O$ conceito de habitus se inspira na proposta de Bourdieu (2002), como uma disposição que vai sendo incorporada, quase posturalmente, interiorizando determinadas estruturas do mundo social. Por sua vez, o habitus alcoólico (Halpern et al., 2008) consolida-se pela existência de certas condições, organização e processos de trabalho que são peculiares à instituição militar naval. Em resposta, ela produz desgaste mental e sofrimento psíquico, acentuando sua experiência de exclusão, e, por fim, 
facilitando a construção do alcoolismo (McLean \& Taylor, 1958, citado por Seligmann-Silva, 1990; Araújo, 1986, citado por Vaissman, 2004; Dejours, 1987; Silva Filho, 1989; Rangel, 1994; Seligmann-Silva, 1995; Borges, 2000; Lacaz, 1996).

Pelos relatos do Cabo Prestes, verifica-se que, além dos militares aprenderem os preceitos e tradições oficiais que são ministrados nas escolas de formação e, permanentemente, atualizados ao longo da carreira, de modo paradoxal, aprendem a ter condutas "marginais", muitas delas "regadas" pelo álcool, em oposição ao que se encontra disposto nos regulamentos internos. Os comportamentos desviantes são, igualmente, aprendidos, fazendo parte de uma "formação extraoficial" para muitos militares. Usualmente, reúnem-se para sair em busca de: aventuras, geralmente amorosas, em locais de risco ("socos suicidas"), "armações" (armador é o enganador, aquele que cria situações para se livrar de responsabilidades), "sair no pulo ou na encolha" (sair escondido), dar uma "escamada" (esquivar-se de trabalhar) e "molhar o bico" (consumir bebida alcoólica) (Maior, 2006).

Por outro lado, o álcool serve como recurso defensivo contra a desindividualização (Velho, 1981) comum no meio militar, onde se espera que o indivíduo seja um membro do corpo institucional. Assim, o álcool seria uma alternativa para escapar da massificação, uma solução individual e/ou grupal para se diferenciar do contingente, para escapar da opressão da hierarquia, arbitrariedade e ambiguidade comuns na interpretação dos regulamentos e na aplicação da disciplina.

Acirrando suas experiências como desviantes dos padrões oficiais, Prestes deu seu passo final na sequência de movimentos que compõem o comportamento marginal, isto é, sua carreira desviante se consolidou ao ser inserido em um grupo também tido como desviante mais organizado, aprendendo com companheiros mais experientes no decurso da interação (Becker, 1977). Trata-se da existência de uma dialética constante entre o estado subjetivo do sujeito e os efeitos psicotrópicos objetivos da droga (Young, 1971). Os consumidores são socializados em grupo no uso da substância; os novatos aprendem a interpretar as sensações físicas com os mais experientes (Velho, 1998). Adicionalmente, constata-se o caráter coercitivo de modelagem social, definindo os contornos do sujeito desviante:

Fomos pro mato; andamos três dias direto! A comida não chegava, só tinha "cana" [cachaça] mesmo. Até que arrumaram um garrafão de cinco litros. O oficial disse: "Quem acha que não guenta beber um litro e não cai, bebe meio litro. Se der azar de cair, eu baixo o cacete!".

Essa experiência indica que não se pode conferir um rótulo de doença ou de contravenção a um comportamento, impondo providências curativas ou medidas disciplinares ao indivíduo sem proceder a uma investigação mais acurada do fenômeno. Trata-se de uma conduta desviante que se encontra em harmonia (total ou parcial) com os costumes locais e que adquire conotações negativas em determinado contexto.

\section{Discussão}

O emprego da ferramenta da narrativa de vida em apenas um indivíduo viabilizou um mergulho nos meandros da experiência laboral de um grupo de trabalhadores pouco estudado, trazendo à tona como os padrões de consumo do álcool podem impregnar a vida de um militar. O estudo em profundidade sobre um único trabalhador é um exercício que ajuda a pensar sobre a situação de outros militares, de difícil acesso, produzindo-se generalizações significativas. De fato, suas falas desnudaram aspectos delicados do dia a dia institucional. No entanto, cabe ressaltar que suas corajosas declarações contribuíram para que a MB desperte, cada vez mais, 
sua atenção para a proteção da saúde de seus trabalhadores e, por conseguinte, assegure que a missão constitucional de defender a pátria seja alcançada.

Embora Prestes seja um alcoólico em recuperação, ele permanece assíduo no póstratamento no Grupo de Consolidação, ajudando-o a (re)construir seus caminhos e (re)significar vários aspectos de sua vida. Com essa mentalidade, ele colocou em marcha seu processo de emancipação como agente de mudança, tornando-se um aliado do CEDEQ e dos Alcoólicos Anônimos (AA), passando a orientar os neófitos. Ele deixou de ser um elemento passivo onde a doença incidia. Do ponto de vista intrapsíquico, ele introjetou a cosmologia disponível no arsenal terapêutico do CEDEQ e dos AAs, onde se desenvolve um ethos que permite aos indivíduos a construção de suas identidades pessoais e coletivas.

Prestes suplantou as questões de poder da ciência oficial que embasa o discurso e práticas da racionalidade médica contemporânea ocidental, autorizada a identificar a doença no sujeito (Luz, 1988), tentando escapar das garras do discurso biomédico hegemônico que tende a alienar os indivíduos de seus processos de adoecimento e cura. Para tal, ele teve que lidar com os esquemas montados de controle e de punição resultantes da capilarização do poder sobre indivíduos e grupos (Foucault, 1979). Além disso, ele conseguiu desatar os nós de um discurso que incrimina e condena a diferença, regulador das fronteiras tênues entre o normal e o patológico, que cria e reproduz os processos de inclusão e de exclusão, de inadaptação e de desvio. Enfim, ele deixou de ser um des-a-filiado social (Castel, 1998), abandonando o rótulo de refugo humano (Bauman, 2005), do sujeito não adaptado ao sistema que o Estado-nação da modernidade acredita ter o direito de excluir.

Como integrante de um segmento minoritário da MB, ele foi atravessado por uma série de intervenções administrativas, coercitivas e médicas, enfim, por tecnologias de poder (Foucault, 2007). Trata-se de uma experiência comum vivida por essa classe ao longo da história da MB que foi alvo do recrutamento forçado nos séculos XVIII e XIX (McBeth, 1977; Costa, 1995; Mendes, 1998; Nascimento, 2001) e de múltiplas formas de punição corporal (Greenhalgh, 1998). Inclusive, Beattie (2004, p. 275) esclarece que: "O próprio termo usado para os soldados alistados, 'praças', localizava-os linguisticamente na rua". A rua assume a condição de ser um espaço relacionado à vadiagem, ilegitimidade, ao perigo, em contraste com a percepção usual do brasileiro da casa, lugar de ordem, segurança, casamento e de família (Freyre, 1936/1977; Da Matta, 1987; Beattie, 2004).

Por outro lado, suas experiências ensinam que seu processo de adoecimento passou a ser um processo de autoconhecimento. De fato, o beber e a farra foram vias de expressão de um eu contido, iludido e subordinado; as "gandaias" foram estratégias úteis para abrir caminho para ele se soltar, maximizando o apequenado eu, sem perspectivas. Sua "doença" foi mais do que um transtorno arrolado no manual de classificação médica de doenças, não podendo ser explicada pela "natureza", mas pelas construções e manipulações da "natureza", cujo significado mais amplo pode ser extraído no interior da organização da sociedade (Vaughan, 1991).

As narrativas de Prestes descortinaram a existência de processos de inclusão e de exclusão em ação, sobretudo por ele ter sido considerado, pelo olhar institucional, um sujeito desviante, representativo da "má sociedade" (Elias \& Scotson, 2000). Sua fala foi reveladora dos significados do "desvio", das formas como ele foi fabricado, das peculiaridades da interação grupal submetida à dinâmica institucional, ancoradas em tradições que reforçam maneiras de beber, de pensar e de comportar-se. Desvio que permite enxergar o indivíduo, o grupo e a organização em sua complexidade. História exclusiva, única, todavia, tão universal. Narrativas de um sujeito que se assemelham às de tantos outros pacientes do CEDEQ e que, segundo informam, não são tão distintas das experiências de outros militares da MB.

Constatou-se que a fronteira entre o consumo de etílicos normal e patológico é sutil, ou melhor, a demarcação entre o beber social, o uso nocivo e a síndrome de dependência do álcool pode ser difícil de ser delimitada. O estudo do consumo de álcool requer a aplicação de medidas 
de quantidade e de frequência de sua ingestão que considerem as distintas sociedades, indivíduos ou grupos sociais em um continuum de padrões de uso (Carlini, 2006).

A própria noção de normalidade e desvio tem um caráter impreciso (Canguilhem, 1978). O comportamento desviante parece emergir quando a conduta padrão rompe a fronteira da norma socialmente estabelecida na organização militar. Geralmente, os "excessos" alcoólicos são esperados e tolerados no cotidiano naval. Porém, mediante o rompimento da linha divisória entre o "certo" e o "errado", a instituição poderá condenar alguns bebedores. Aquilo que era (extra) oficialmente padrão - a tradição do beber - converte-se em contravenção. A distinção entre o consumo normal e patológico se esclarece quando as maneiras prescritas de beber são descumpridas, quando o acordo tácito em torno das convenções sobre as formas de beber é rompido.

Todavia, em que momento se dá o rompimento "contratual"? Quando os superiores hierárquicos deixam de fazer "vista grossa"? Isso parece ocorrer quando, de maneira explícita e frontal, as falhas laborais decorrentes do uso de bebidas melindram a autoridade ou a administração do Comando, imprimindo uma conotação negativa ao bebedor e seus desacertos. Suas condutas tortas são enquadradas como contravenções, passíveis de punição e de medidas administrativas e/ou médicas. A partir dessa nova percepção, o erro torna-se material, palpável, exigindo um posicionamento ostensivo, público e objetivo. E, uma vez que a falha é materializada, impõe-se um pronunciamento oficial: administrativo/militar.

Consequentemente, o indivíduo passa a destoar do grupo uniforme, sendo considerado um "infrator" ou "doente". Sua existência torna-se impregnada pelos efeitos negativos advindos daquele ato, contaminando o resto de sua vida profissional ou pessoal, mesmo que tenha sido uma experiência isolada e fortuita. No entanto, essa falha pode dar início a uma sucessão de desacertos, como se deu com Prestes, tatuando, em seu íntimo, um traço que antes era nublado e difuso. Um estigma é colado, conferindo-lhe uma identidade marginal. Em resposta, a organização, por rituais administrativos, batiza o sujeito com a identidade desviante, passando a ser reconhecido como tal. Seu deslize o define. Ao ser denunciado pelos critérios hegemônicos institucionais, o ato desviante é identificado, sendo-lhe prescrito um corretivo a ser registrado em seus assentamentos profissionais. Seu erro ganha primazia sobre qualquer outro aspecto de sua vida profissional ou característica de personalidade, ainda que tenha sido, até então, um episódio excepcional.

A ordem é restabelecida com a aplicação exemplar do Regulamento, código éticomoral, legitimador dos padrões normativos de condutas e definidor dos critérios de normalidade. Com a punição, a homeostase é recuperada, não em função da Lei, mas pelo interesse contingencial em cumpri-la. Trata-se de um dispositivo regulamentar que tende a ser aplicado de acordo com as circunstâncias, movido por políticas, por afetos ou desafetos, ou pelas emoções motivadas por medos ou paixões. Aspectos subjetivos da autoridade militar são determinantes para motivar a "canetada" e o "carimbo", que sentencia e sela uma marca intransponível e absoluta, atribuindo um "rótulo" perene na carreira e subjetividade do subordinado. A partir daí, consuma-se um dos passos mais cruciais da construção de um padrão estável de comportamento desviante, conforme assinala Becker (1977): a experiência de ser apanhado e publicamente estigmatizado como desviante. Esse evento traz importantes consequências para sua autoimagem e participação social, conferindo-lhe uma identidade pública, um novo status, um traço-chave que o distingue. É curioso perceber como uma cicatriz desviante indesejável ganha predominância e é generalizada para o todo de uma pessoa. Esse rótulo nefasto se converte em seu status principal, agindo como uma profecia autorrealizável, moldando o sujeito de acordo com a visão criada a seu respeito. Enfim, a crença de que um fato seja verdadeiro pode provocar sua própria concretização (Merton, 1949/1970).

$\mathrm{Na}$ verdade, a busca por sua individualidade talvez seja uma das questões mais marcantes na trajetória de Prestes. Inspirado nas figuras hollywoodianas idealizadas na 
juventude, ele havia construído uma imagem de si mesmo como FN capaz de arrancar o cadeado e correntes vermelhos. Paradoxalmente, foi no próprio universo fuzileiro, com seu novo status de militar, que ele sucumbiu, até ser arrastado pelas circunstâncias para travar uma batalha inesperada pela sua individualização. $O$ álcool foi metáfora dessa oposição: libertando e aprisionando. Por um lado, diferenciando-o, de forma efêmera, do conjunto; por outro, arremessando-o de volta ao confinamento dos elos rubros. Sua trajetória em busca de sua afirmação como sujeito foi traçada, com linhas tortas, cambaleando entre normalidade e desvio. Porém, mormente, ela foi tenaz e vitoriosa.

\section{Considerações finais}

Por ocasião das entrevistas, Prestes ainda aguardava a decisão das autoridades navais que, estranhamente, oscilavam entre autorizá-lo a participar de um curso preparatório para poder ser promovido a Sargento, ou encaminhá-lo para a reforma (aposentadoria por problemas de saúde). Na atualidade, ele conseguiu suplantar heroicamente o rótulo de desviante e superar os obstáculos, tornando-se um "dependente químico em recuperação", transformando aspectos de sua personalidade e estilo de vida. Desde seu ingresso no CEDEQ e nos AAs, converteu-se em alcoólico passivo (Garcia, 2004), agregando representações construídas nesses espaços terapêuticos, o que lhe permitiu redigir uma nova narrativa, na qualidade de militante dessa causa e de colaborador de sua divulgação. As próprias entrevistas ajudaram-no a dar um novo sentido à sua cegueira parcial e às limitações na carreira. Com isso, ele ampliou sua forma de se perceber, (re)construindo sua história de vida. Recentemente, contou que, finalmente, havia conseguido a ansiada promoção. $\mathrm{O}$ "sonho fuzileiro" continuava de pé! A cisão entre a carreira e a reforma se dissolveu na solução derradeira da administração naval, autorizando-o a cursar, condição necessária à ansiada promoção para obter a graduação de Sargento, fruto de um "plantio" perseverante nos últimos anos: "colheita" meritória!

\section{Referências}

Alberti, V. (2004). Ouvir contar: textos em história oral. Rio de Janeiro: FGV.

Bauman, Z. (2005). Vidas desperdiçadas. Rio de Janeiro: Zahar.

Beattie, P. M. (2004). Ser homem pobre, livre e honrado: a sodomia e os praças nas Forças Armadas brasileiras

(1860-1930). In C. Castro, V. Izecksohn \& H. Kraay (Org.), Nova história militar brasileira (pp. 269-299). Rio de Janeiro: FGV.

Becker, H. S. (1977). Uma teoria da ação coletiva. Rio de Janeiro: Zahar.

Bourdieu, P. (2002). A produção da crença: contribuição para uma economia dos bens simbólicos. São Paulo: Zouk.

Borges, L. H. (2000). Trabalho em processos repetitivos: sociabilidade, sofrimento psíquico e lesões por esforços repetitivos (L. E. R.). In Organização do trabalho e saúde mental. (Cadernos Ipub) (pp. 67-80). Rio de Janeiro: Ipub.

Brasil. (1980). Lei n. 6.880, de 9 de dezembro de 1980. (1980, 11 de dezembro). Dispõe sobre o Estatuto dos Militares. Diário Oficial da União, seção 1.

Canguilhem, G. (1978). O normal e o patológico. Rio de Janeiro: Forense Universitária.

Carlini, B. (2006). O uso de drogas psicotrópicas no Brasil. In Secretaria Nacional Antidrogas e Serviço Social da Indústria (Org.), Prevenção ao uso de álcool e outras drogas no ambiente de trabalho: conhecer para ajudar (pp. 63-76). Brasília, DF: Secretaria Nacional Antidrogas e Serviço Social da Indústria.

Castel, R. (1998). As metamorfoses da questão social. Petrópolis, RJ: Vozes. 
Castro, C. (2004). O espírito militar: um antropólogo na caserna. Rio de Janeiro: Zahar.

Coelho, E. C. (1976). Em busca de identidade: o Exército e a política na sociedade brasileira. Rio de Janeiro: Forense Universitária.

Costa, F. D. (1995). Os problemas do recrutamento militar no final do século XVIII e as questões da construção do estado e da nação. Análise Social, 30 (130), 121-155.

Da Matta, R. (1987). A casa e a rua: espaço, cidadania, mulher e morte no Brasil. Rio de Janeiro: Guanabara.

Dejours, C. (1987). A loucura do trabalho: estudo de psicopatologia do trabalho. São Paulo: Oboré.

Dejours, C. (1999). Conferências brasileiras: identidade, reconhecimento e transgressão no trabalho. São Paulo: FGV.

Elias, N. (1987). A sociedade de corte. Lisboa: Estampa.

Elias, N. \& Scotson, J. L. (2000). Os estabelecidos e os outsiders: sociologia das relações de poder a partir de uma pequena comunidade. Rio de Janeiro: Zahar.

Freyre, G. (1977). Sobrados e mucambos: decadência do patriarcado rural e desenvolvimento do urbano. Rio de Janeiro: José Olympio. (Trabalho original publicado em 1936).

Garcia, A. (2004). E o verbo (re)fez o homem: estudo do processo de conversão do alcoólico ativo em alcoólico passivo. Rio de Janeiro: Intertexto.

Geertz, C. (1973). The interpretation of cultures. New York: Basic Books.

Groleau, D., Young, A. \& Kirmayer, L. J. (2006). The McGill illness narrative interview (MINI): an interview schedule to elicit meanings and modes of reasoning related to illness experience. Transcultural Psychiatry, 43 (4), 671-691.

Foucault, M. (1979). Microfísica do poder. Rio de Janeiro: Graal.

Foucault, M. (2007). Vigiar e punir: nascimento da prisão. Petrópolis, RJ: Vozes.

Goffman, E. (2008). Estigma: notas sobre a manipulação da identidade deteriorada (4a ed.). Rio de Janeiro: LTC. (Trabalho original publicado em 1963).

Greenhalgh, J. F. L. (1998). Presigangas e calabouços ou prisões da Marinha no Século XIX. Rio de Janeiro: Serviço de Documentação da Marinha.

Halpern, E. E., Ferreira, S. M. B. \& Silva Filho, J. F. (2008). Os efeitos das situações de trabalho na construção do alcoolismo de pacientes militares da Marinha do Brasil. Cadernos de Psicologia Social do Trabalho, 11 (2), 273-286.

Holstein, J. A. \& Gubrium, J. F. (1995). The active interview. Thousand Oaks, CA: Sage.

Lacaz, F. A. C. (1996). Saúde do trabalhador; um estudo sobre as formações discursivas da academia, dos serviços e do movimento sindical. Tese de Doutorado, Universidade Estadual de Campinas, Campinas.

Lambek, M. (1996). The past imperfect: remembering as moral practice. In P. Antze \& M. Lambek (Org.), Tense past: cultural essays in trauma and memory (pp. 235-254). London: Routledge.

Luz, M. T. (1988). Natural, racional, social: razão médica e racionalidade científica moderna. Rio de Janeiro: Campus.

Maior, R. S. (2006). Rolo de japona: dicionários, contos e crônicas do linguajar marinheiro (praças). São Paulo: Scortecci.

Mauss, M. (1974). As técnicas corporais. In M. Mauss, Sociologia e antropologia, com uma introdução à obra de Marcel Mauss, de Claude Lévi-Strauss (pp. 211-233). São Paulo: EPU.

McBeth, M. G. (1977). The Brazilian recruit during the First Empire: slave or soldier? In D. Alden \& W. Dean (Ed.), Essays concerning the socioeconomic history of Brazil and Portuguese India (pp. 71-86). Gainesville: The University Presses of Florida.

Mendes, F. F. (1998). A economia moral do recrutamento militar no Império brasileiro. Revista Brasileira de Ciências Sociais, 13 (38).

Merton, R. K. (1970). Sociologia: teoria e estrutura. São Paulo: Mestre Jou. (Trabalho original publicado em 1949).

Nascimento, A. P. (2001). A ressaca da marujada: recrutamento e disciplina na Armada Imperial, 1880-1919. Rio de Janeiro: Arquivo Nacional.

O’Donnell, J. G. (2008). De olho na rua: a cidade de João do Rio. Rio de Janeiro: Zahar.

Rangel, M. L. (1994). Risco e saúde nos locais de trabalho. Gênero, prática médica e saúde. Physis: Revista de Saúde Coletiva, 4 (1), 133-145.

Rodrigues, F. L. (2004). Vozes do mar: o movimento dos marinheiros e o golpe de 64. São Paulo: Cortez.

Seligmann-Silva, E. (1990). Saúde mental e trabalho. In S. A. Tundis \& N. F. Costa (Org.), Cidadania e loucura: políticas de saúde mental no Brasil (pp. 217-287). Petrópolis, RJ: Vozes.

Seligmann-Silva, E. (1995). Psicopatologia e psicodinâmica no trabalho. In R. Mendes (Org.), Patologia do trabalho (pp. 287-310). Rio de Janeiro: Atheneu.

Silva, C. (1961). Histórias de fuzileiros navais brasileiros (subsídios para a história do Corpo de Fuzileiros Navais). Guanabara: Folha Carioca.

Silva Filho, J. F. (1989). Saúde mental e trabalho. Dissertação de Doutorado, Instituto de Psiquiatria, Universidade Federal do Rio de Janeiro, Rio de Janeiro.

Thompson, P. (1992). A voz do passado: história oral. Rio de Janeiro: Paz e Terra.

Vaissman, M. (2004) Alcoolismo no trabalho (Coleção Loucura XXI). Rio de Janeiro: Garamond.

Vaughan, M. (1991). Curing their ills: colonial power and African illness. Stanford, CA: Stanford University Press.

Velho, G. (1981). Projeto, emoção e orientação em sociedades complexas. In G. Velho (Org.), Individualismo e cultura: notas para uma antropologia da sociedade contemporânea (pp. 13-38). Rio de Janeiro: Zahar.

Velho, G. (1994). Projeto e metamorfose: antropologia das sociedades complexas. Rio de Janeiro: Zahar.

Velho, G. (1998). Nobres $\mathcal{E}$ anjos: um estudo de tóxicos e hierarquia. Rio de Janeiro: FGV. 
Yin, R. K. (2005). Estudo de caso: planejamento e métodos. Porto Alegre: Bookman.

Young, J. (1971). The drugtakers: the social meaning of drug use. London: Paladin.

\section{Endereço para correspondência}

espindolahalpern@yahoo.com.br, ligialeite@invenciveis.com 